\title{
Waterpipe smoking and dependence are associated with chronic bronchitis: a case-control study in Lebanon
}

\author{
P. Salameh, ${ }^{1,2}$ M. Waked, ${ }^{3}$ F. Khoury, ${ }^{2}$ Z. Akiki, ${ }^{2}$ Z. Nasser, ${ }^{2}$ L. Abou Abbass, ${ }^{2}$ M. Dramaix ${ }^{4}$ for the Chronic Bronchitis Study Group
}

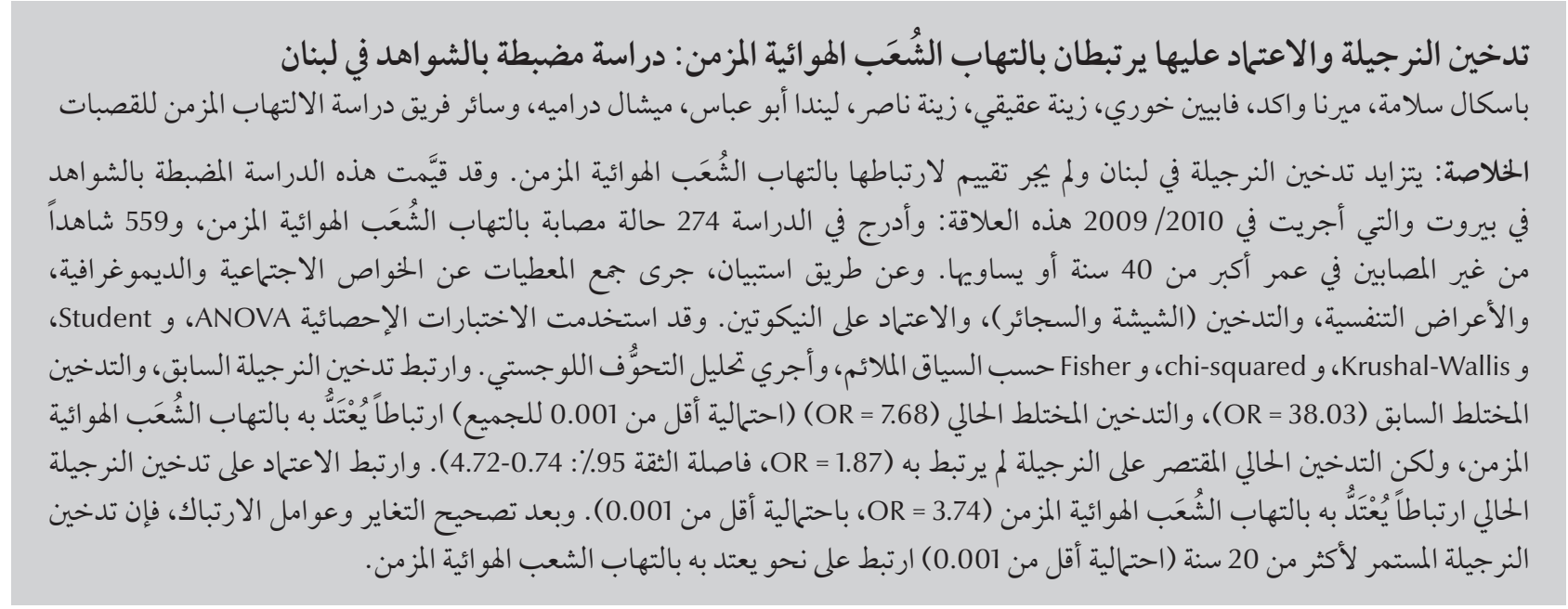

ABSTRACT Waterpipe smoking and its association with chronic bronchitis has not been assessed in Lebanon. This case-control study in Beirut in 2009/2010 evaluated this relationship: 274 cases of chronic bronchitis and 559 controls without the condition aged $\geq 40$ years were enrolled. Data were collected by questionnaire on: sociodemographic characteristics, respiratory symptoms, smoking (waterpipe and cigarette) and nicotine dependence. ANOVA, Student, Kruskal-Wallis, chi-squared and Fisher exact tests were used when applicable and logistic regression analysis was carried out. Previous waterpipe smoking $(O R=6.4)$, previous mixed smoking $(O R=$ 38.03) and current mixed smoking $(\mathrm{OR}=7.68)$ were significantly associated with chronic bronchitis $(P<0.001$ for all $)$ but current exclusive waterpipe smoking was not $(\mathrm{OR}=1.87,95 \% \mathrm{Cl}: 0.74-4.72)$. Current waterpipe dependence was significantly associated with chronic bronchitis $(\mathrm{OR}=3.74, P<0.001)$. After adjustment for covariates/confounders, ever waterpipe smoking $>20$ WP-years $(P<0.001)$ was significantly associated with chronic bronchitis.

\section{Narguilé et dépendance et association avec la bronchite chronique : étude cas-témoins au Liban}

RÉSUMÉ L'usage du narguilé et son association avec la bronchite chronique n'ont pas été évalués au Liban. La présente étude cas-témoins à Beyrouth en 2009 et 2010 a évalué cette association : 274 cas de bronchite chronique et 559 témoins en bonne santé âgés de 40 ans et plus ont été recrutés. Les données suivantes ont été recueillies au moyen d'un questionnaire : caractéristiques sociodémographiques, symptômes respiratoires, consommation de tabac (narguilé et cigarettes) et dépendance à la nicotine. L'analyse de la variance (ANOVA), les tests de Student, de Kruskal-Wallis, du khi-carré et de Fisher ont été utilisés lorsqu'ils étaient pertinents et une analyse de régression logistique a été menée. Des antécédents d'utilisation du narguilé $(O R=6,4)$ et de consommation mixte de tabac antérieure à l'étude $(O R=38,03)$ et au moment de l'étude $(O R=7,68)(P<0,001$ pour tous $)$ étaient significativement associés à une bronchite chronique alors que l'utilisation exclusive du narguilé au moment de l'étude ne l'était pas $(\mathrm{OR}=1,87$; IC à $95 \%$ : 0,74-4,72). Une dépendance au narguilé au moment de l'étude était significativement associée à une bronchite chronique $(\mathrm{OR}=3,74 ; P<0,001)$. Après ajustements pour des co-variables/des facteurs de confusion, une consommation supérieure à 20 narguilés-an à un moment donné dans le passé $(P<0,001)$ était significativement associée à une bronchite chronique.

${ }^{7}$ Faculties of Pharmacy; 2Public Health, Lebanese University, Beirut, Lebanon (Correspondence to P. Salameh: psalameh@ul.edu.lb; pascalesalameh1@hotmail.com). ${ }^{3}$ Faculty of Medicine, Saint George Hospital \& Balamand University, Beirut, Lebanon. ${ }^{4}$ Faculty of Medicine, School of Public Health, Université Libre de Bruxelles, Brussels, Belgium. ${ }^{5}$ The Chronic Bronchitis Study Group also includes: G. Khayat, S.Azizi, D. Saadeh, A Akhdar, C. Ziadeh and J. Salame.

Received: 22/09/11; accepted: 24/11/11 


\section{Introduction}

Waterpipe smoking is a form of tobacco smoking that is witnessing a surge in popularity all over the world [1-4]. Concerns about the health risk of waterpipe smoking have been voiced $[5,6]$, and the few studies conducted about the health effects suggest that it leads to cancer, genetic damage, diseases of the lungs and other conditions in active and passive smokers [7-12]. A recent systematic review highlighted the association of waterpipe smoking with lung cancer and respiratory illness among other deleterious effects [13]. Thus, waterpipe is considered by the World Health Organization (WHO) a global public health threat [5], and given the increasing number of people smoking the waterpipe, it is essential to study its health effects with renewed emphasis [14].

In Lebanon, waterpipe smoking prevalence is one of the highest in the WHO Eastern Mediterranean Region: $25 \%$ in school students (versus $9 \%$ $16 \%$ in Gulf countries), 28\% among university students (versus 6\% in Gulf countries, $15 \%$ in the Syrian Arab Republic and 33\% in Pakistan), and $15 \%$ among adults (versus $4 \%-12 \%$ in Gulf countries and 9\%-12\% in the Syrian Arab Republic) [15]. There are numerous reasons for this, including its availability, affordability, novelty, influence of media, lack of enforcement of antismoking laws, and its perceived associated pleasurable effects [16].

In a previous study, we validated the first dependence scale for waterpipe smoking, the Lebanon Waterpipe Dependence Scale - 11 (LWDS-11). This scale was able to discriminate between mild, moderate and heavy waterpipe smokers [17]. Waterpipe smoking is thus a habit that has dimensions of physiological (nicotine dependence), psychological (positive and negative reinforcement, craving) and social nature (conviviality and group smoking) [17], and it may manifest in several patterns in real life. A substantial percentage of waterpipe smokers may not depend on it (50\%-80\%, according to the quantity smoked), and may thus smoke irregularly [18]. In a national cross-sectional study on adults aged $\geq 40$ years, $45.3 \%$ of current waterpipe smokers were dependent on it; $60 \%$ were exclusive waterpipe smokers while $40 \%$ smoked both cigarettes and the waterpipe [19].

Chronic bronchitis increases the risk of infections and lung cancer; it may also progress to and constitute a part of chronic obstructive pulmonary disease (COPD) [20]. Although cigarette smoking is the most important cause of chronic bronchitis, waterpipe smoking seems to have health effects similar to those of cigarette smoking [5]. In a previous pilot study, we found relative risks of 2.5 of physician-diagnosed respiratory diseases and self-reported chronic bronchitis symptoms in waterpipe smokers versus never smokers [21].

The objective of this study therefore was to evaluate the association between waterpipe smoking, waterpipe dependence and chronic bronchitis in a clinical setting. Waterpipe smoking and waterpipe dependence were the exposure variables of interest, while the outcome variable was chronic bronchitis, defined as abnormal production of mucus causing airflow obstruction and inflammatory changes in the bronchial mucosa leading to chronic productive cough for at least 3 months of the year for at least 2 years [22].

\section{Methods}

\section{Study design}

We conducted a case-control study in 2 tertiary care hospitals in Beirut between July 2009 and June 2010, comparing a group of patients with chronic bronchitis with a control group. Exposure to waterpipe smoking, waterpipe dependence and sociodemographic characteristics were compared between the 2 groups.
Since the study was observational and there participants would be untraceable, the Internal Review Board (IRB) of the Lebanese University waived the need for official approval to perform the study, provided the study respected patients' autonomy and confidentiality. No incentive was given to participants and they were free to participate or not after a verbal explanation of the study objectives. The recorded data were anonymous and no names were entered.

\section{Study population}

The chronic bronchitis group (cases) was composed of incident or prevalent outpatient cases of patients who were newly diagnosed as chronic bronchitis by a chest physician and who responded positively to the question: "Have you had a productive morning cough for more than 3 months a year for more than 2 years?" [23]. Inclusion criteria were: age $\geq 40$ years, and free of other diagnosed respiratory diseases such as asthma, tuberculosis, lung cancer or fibrosis. The exclusion criterion was: previous diagnosis of COPD.

The control group was drawn from outpatients consulting for a variety of problems (renal and urological, gastrointestinal, orthopaedic and rheumatologic, cardiologic, endocrinological, gynaecological, and ophthalmological problems and pre-surgery consultation) and were free of any respiratory disease or symptom. Moreover, people accompanying cases (family members or friends) could also be taken as controls. Inclusion criterion was age $\geq 40$ years. Exclusion criteria were: previous or current diagnosis of chronic bronchitis or COPD, any other diagnosed respiratory diseases such as asthma, tuberculosis, lung cancer or fibrosis; any chronic respiratory symptom.

\section{Data collection}

Patients were approached by local interviewers (spirometry technicians) after referral of all patients fulfilling inclusion 
criteria by the pulmonologists. After informed verbal consent, a standardized questionnaire was used to evaluate the following: detailed cigarette and waterpipe smoking history, passive smoking at home and at work (determined by the number of smokers at home and work, both cigarette and waterpipe), exposure to smoke and fumes at work and home (determined self-reported exposure to toxic gases and fumes), history of residency in polluted areas (ever living close to a local power plant/busy road), cigarette and waterpipe dependence scores according to Fagerström Test for Nicotine Dependence (FTND) [24] and LWDS-11 [17] respectively. Waterpipe dependence was defined as having a score of $\geq 10$ on LWDS11 [17]. Other potential confounding variables evaluated by the questionnaire included age, sex, education level, work status and marital status. Chronic bronchitis diagnosis was made after clinical and epidemiological testing: patients were evaluated for chronic respiratory symptoms such as dyspnoea, chronic cough, and chronic expectorations, using the American Thoracic Society questionnaire [25].

While the LWDS-11 was specifically developed for the Lebanese context, it showed an adequate internal consistency (Cronbach alpha $=0.83)$ and construct validity $(r=0.72-0.78$ for correlation with saliva carbon monoxide) [17]. The FTND is an internationally used scale with variable but acceptable levels of validity and reliability [26]; it was adapted to Lebanon by translation into Arabic and back translation into English. The same translation procedure was applied for the American Thoracic Society questionnaire for respiratory symptoms.

\section{Sample size calculation}

We assumed an exposure probability to waterpipe smoke of 0.5 (representing the mean $50 \%$ of Lebanese adults individuals who smoke and could theoretically be exposed to waterpipe smoke) [27] and at least 20\% of these were dependent on the waterpipe [17] making $10 \%$ of the general population waterpipe-dependent. Therefore with 95\% confidence interval and power of $80 \%$, the minimal sample size necessary to show a twofold increase in the risk of chronic bronchitis was 721 subjects, 515 controls and 206 cases. We increased the number of subjects above the minimum necessary to allow for possible missing values.

\section{Statistical analysis}

Data entry was performed by independent lay persons who were unaware of the objectives of the study. Quality control of data entry and data cleaning were carried out by the authors. Statistical analysis was performed using SPSS, version 13.0. A $P$-value of 0.05 was considered statistically significant.

For between-group comparison for continuous variables, we used ANOVA or Student tests for variables with adequate normal distribution. For non-normally distributed continuous variables and for discrete quantitative and ordinal variables, the Kruskal-Wallis test was used. For categorical variables, the chi-squared and Fisher exact tests were used when applicable.

The dependent variable was: being diagnosed with chronic bronchitis. Independent variables were: waterpipe smoking and waterpipe dependence score. Dose-effect relationships were evaluated by trend tests. A stratified analysis was carried out for cigarette smoking and waterpipe smoking and dependence to test for interactions.

Multivariate analyses were carried out to compare measures between comparison groups, taking into account potential confounding variables that had a $P$-value $<0.20$ in the bivariate analysis: ever cigarette smoking, sex, residency, age, education, work status and marital status. Logistic regression was chosen because the dependent variable was dichotomous: a stepwise descendent likelihood ratio logistic regression was applied, and the final models were reached. Point estimates, 95\% confidence intervals (CIs) and $P$-values are presented. The major independent variables were ever smoking (> 20 waterpipe-years) and waterpipe dependence (score of $\geq 10$ on LWDS11). Interaction between waterpipe smoking/waterpipe dependence and ever smoking cigarettes was examined. The final models were accepted after determining adequacy of the fit with the Hosmer \& Lemeshow test. Subgroup analyses were also carried out.

\section{Results}

\section{Population}

A total of 833 individuals were included in the study: 274 cases of chronic bronchitis and 559 controls without the condition. There was a refusal rate of no more than $10 \%$ (2\% of cases and $10 \%$ of controls).

Of the 274 cases, 121 (44.2\%) were ever told by their doctor that they suffered from a chronic respiratory disease and $42(15.3 \%)$ had been hospitalized at least once due to their respiratory problem. In addition, 112 (40.9\%) reported that in the last 12 months, they had periods with more cough and expectorations than usual.

As for the 559 controls, 355 (63.5\%) reported themselves totally healthy with no chronic diseases or symptoms; the rest were classified as follows: 42 (7.5\%) were consulting for cardiology problems, 15 (2.7\%) for endocrinology, 19 (3.4\%) for dermatology, 9 (1.6\%) for haematology/oncology, 8 (1.4\%) for nephrology, 9 (1.6\%) for urology, 19 (3.4\%) for gastroenterology, 8 (1.4\%) for gynaecology, 17 (3.04\%) for ophthalmology, 3 (0.5\%) for otorhinolaryngology and 15 (2.7\%) for pre-surgery consultation. Forty patients (7.2\%) did not give the reason for their medical consultation and we could not follow up on their files because the data we gathered were anonymous. 


\section{Baseline characteristics}

Table 1 gives baseline characteristics of the cases and controls. There were significant differences between cases and controls: cases were older $(P<$ $0.001)$, with more males $(P<0.007)$, had a lower education $(P<0.001)$, were retired or never worked $(P<0.001)$, and were widowed or divorced $(P<0.001)$ (Table 1).

\section{Smoking history}

Compared to never smokers, all types of smoking, except passive smoking at work, were associated with a higher risk of chronic bronchitis, although with different strengths of association (Table 2). For ex-smokers, waterpipe smokers had a 6-times increased risk of chronic bronchitis (OR $=6.40,95 \%$ CI: 2.55-16.11, $P<0.001)$ while for current smokers, waterpipe smokers had a 1.87-times increased risk of chronic bronchitis (OR $=1.87,95 \%$ CI: 0.74-4.72, $P<0.001)$. Exclusive waterpipe dependence $(\mathrm{OR}=3.74$, 95\% CI: $1.24-7.58, P<0.001)$ and being exposed to any type of passive smoking at home $(\mathrm{OR}=3.09,95 \%$ CI: 2.25-4.23, $P<0.001)$ also showed strong associations with chronic bronchitis.

Comparing current waterpipe-dependent individuals with never smokers and non-dependent waterpipe smokers gave an OR for chronic bronchitis of 7.11 (95\% CI: 3.57-14.17, $P<$ $0.001)$.In the waterpipe-dependent group, $32.3 \%$ had chronic bronchitis, compared with $6.3 \%$ in the non-waterpipe-dependent and non-smoker groups. Stratifying by cigarette smoking and cigarette dependence showed no qualitative interaction $(P=0.17$ and $P=0.43$ respectively). In the waterpipe smoker and never smoker subgroups, cases had a mean LWDS11 score of 11.05, while controls had a mean of $2.98(P<0.001)$; in exclusive waterpipe smokers, the scores were 18.88 for cases and 11.59 for controls $(P<0.001)$.

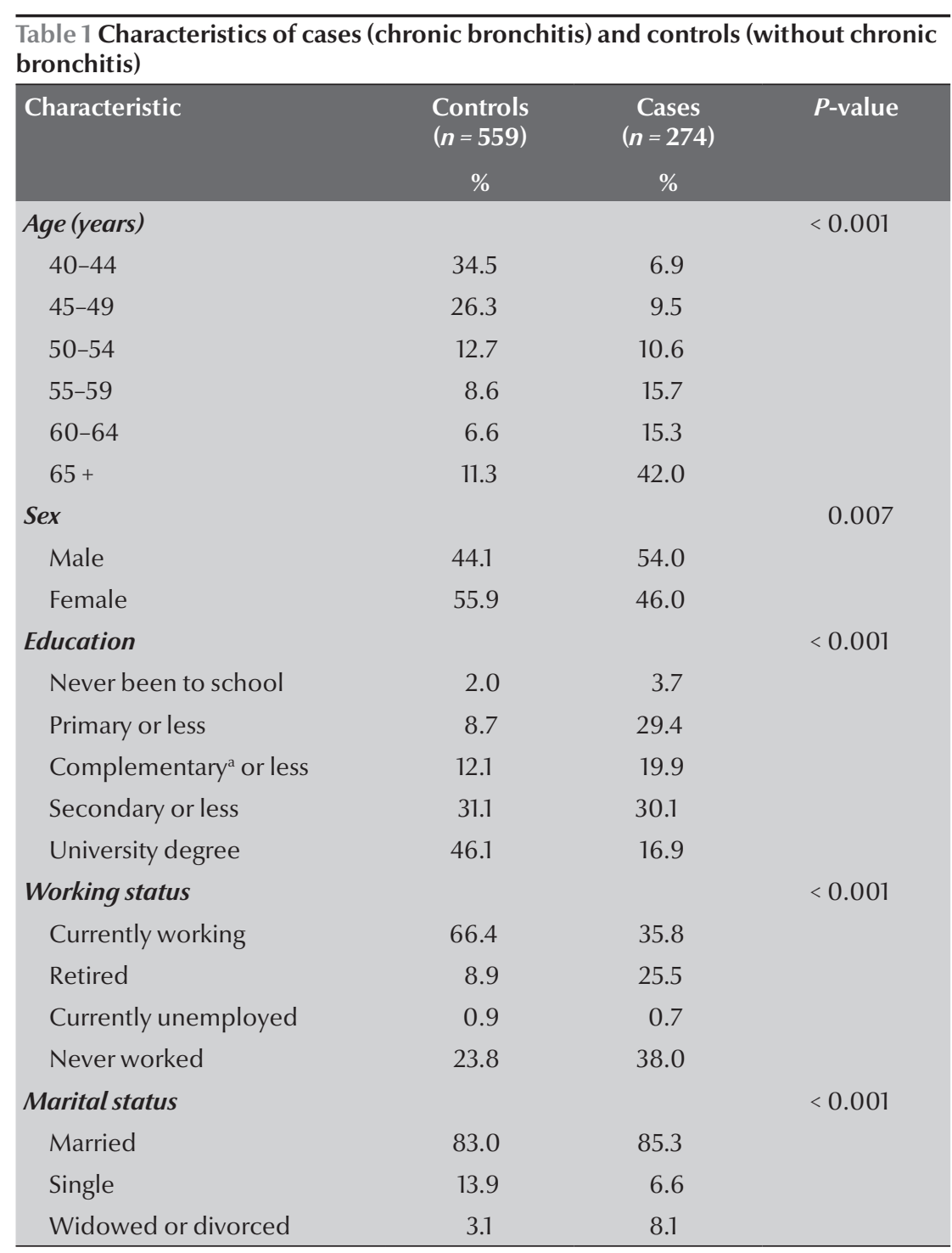

${ }^{a}$ Up to 15 years of age.

Comparing ex-waterpipe smokers with never smokers gave an OR for chronic bronchitis of 17.28 (95\% CI: 8.74-34.16, $P<0.001)$. In this case, no stratified analysis could be performed because all the individuals in the cigarette smoker subgroup were also waterpipe smokers.

\section{Dose-effect relationships}

Statistically significant dose-effect relationships were found for all kinds of smoking (Table 3): higher cumulative doses and frequencies and durations of smoking for all groups (ex-cigarette, ex-waterpipe, current cigarette and current waterpipe) were all associated with an increased risk of chronic bronchitis $(P<0.001)$ (Table 3).

There was a positive and significant trend of increased chronic bronchitis with increasing waterpipe dependence score with never smokers as the reference category (chronic bronchitis prevalence $=6.3 \%)$. The higher the dependence score on LWDS-11, the higher the odds of chronic bronchitis: $6.7 \%$ of those with chronic bronchitis were non-dependent waterpipe smokers (LWDS-11=1-9) (OR=1.07, 95\% CI: $0.30-3.80$ ), 8.0\% were moderately dependent (LWDS$11=10-16)(\mathrm{OR}=1.30,95 \% \mathrm{CI}$ : $0.28-5.98$ ), while $45.2 \%$ were highly dependent (LWDS-11 >16) (OR 


\begin{tabular}{|c|c|c|c|c|}
\hline \multirow[t]{2}{*}{ Variable } & Controls $(n=559)$ & Cases $(n=274)$ & $P$-value & OR $(95 \% \mathrm{Cl})$ \\
\hline & No. (\%) & No. (\%) & & \\
\hline Previous smoking & $(n=366)$ & $(n=140)$ & $<0.001$ & \\
\hline Never smoker ${ }^{\mathrm{a}}$ & $254(69.4)$ & 17 (12.1) & & 1.00 \\
\hline Cigarette smoker & 80 (21.9) & $86(61.4)$ & & $16.06(9.01-28.62)$ \\
\hline Waterpipe smoker & $21(5.7)$ & $9(6.4)$ & & $6.40(2.55-16.11)$ \\
\hline Mixed smoker & $11(3.00$ & $28(20.0)$ & & $38.03(16.21-89.24)$ \\
\hline Current smoking & $(n=455)$ & $(n=162)$ & $<0.001$ & \\
\hline Never smoker ${ }^{\mathrm{a}}$ & $254(55.8)$ & $17(10.5)$ & & 1.00 \\
\hline Cigarette smoker & $110(24.2)$ & $120(74.1)$ & & $16.30(9.34-28.39)$ \\
\hline Waterpipe smoker & $56(12.3)$ & $7(4.3)$ & & $1.87(0.74-4.72)$ \\
\hline Mixed smoker & $35(7.7)$ & $18(11.1)$ & & 7.68 (3.63-16.29) \\
\hline Actual tobacco dependence ${ }^{b}$ & $(n=332)$ & $(n=107)$ & $<0.001$ & \\
\hline Never smoked ${ }^{a}$ & $254(76.5)$ & 17 (15.9) & & 1.00 \\
\hline Cigarette dependence & 35 (10.5) & $74(69.2)$ & & 31.59 (16.75-59.59) \\
\hline Waterpipe dependence & 39 (11.7) & $8(7.5)$ & & $3.74(1.24-7.58)$ \\
\hline Mixed dependence & $4(1.2)$ & $8(7.5)$ & & $29.88(8.17-109.30)$ \\
\hline Passive smoking at home & $(n=559)$ & $(n=274)$ & $<0.001$ & \\
\hline No & $298(53.3)$ & $74(27.0)$ & & $3.09(2.25-4.23)$ \\
\hline Yes & $261(46.7)$ & $200(73.0)$ & & 1.00 \\
\hline Passive smoking at work & $(n=559)$ & $(n=274)$ & 0.557 & \\
\hline No & $472(84.4)$ & $227(82.8)$ & & $1.12(0.76-1.66)$ \\
\hline Yes & $87(15.6)$ & $47(17.2)$ & & 1.00 \\
\hline
\end{tabular}

${ }^{a}$ Never smokers are the same in all 3 comparisons; ${ }^{b}$ Waterpipe dependence was measured by the Lebanese Waterpipe Dependence Scale-11 and cigarette dependence by the Fagerström Test for Nicotine Dependence.

$O R=$ odds ratio; $\mathrm{Cl}=$ confidence interval.

= 12.34, 95\% CI: 5.65-26.96) $(P<$ 0.001 for trend).

\section{Multivariate and subgroup analyses}

Table 4 shows the multivariate analyses for the association between chronic bronchitis and waterpipe smoking in the whole sample and in subgroups. A stepwise descendent logistic regression was run, taking waterpipe smoking of $\geq 20$ waterpipe-years as a major independent variable $(n=824 ; 272$ chronic bronchitis cases and 552 controls; there were some patients with missing values on some covariates), the final model adequately fit the data: Nagelkerke $R^{2}$ $=0.546$ and Hosmer \& Lemeshow test $P$-value $=0.062 ; 81.6 \%$ of individuals were adequately classified by the model.

There was a significant positive association between ever waterpipe smoking and chronic bronchitis after adjusting for all the covariates (adjusted $\mathrm{ORa}=2.75,95 \% \mathrm{CI}: 1.48-5.09, \mathrm{P}=$ 0.001). After adjustment, all the other covariables except ever living close to a power plant $(\mathrm{ORa}=1.50, P=0.075)$ were also significantly associated with chronic bronchitis. The interaction term was removed from the analysis model because it was not significant.

Among the waterpipe smokers, when taking waterpipe smoking of $\geq 20$ waterpipe-years as a major independent variable $(n=180 ; 61$ chronic bronchitis cases and 119 controls), the final model adequately fit the data: Nagelkerke $\mathrm{R}^{2}=$ 0.765 and Hosmer \& Lemeshow test $P$ value $=0.884 ; 87.8 \%$ of individuals were adequately classified by the model. Waterpipe smoking significantly increased the risk of chronic bronchitis $(\mathrm{ORa}=$ 5.65, 95\% CI: $1.58-20.23, P=0.008)$.
Older age, ever cigarette smoking, female gender, lower education, ever living close to a local power plant and air conditioning on heating mode all increased the risk of chronic bronchitis.

In the cigarette smokers subgroup, when taking waterpipe smoking $\geq 20$ waterpipe-years as a major independent variable $(n=480 ; 251$ chronic bronchitis cases and 229 controls), the final model adequately fitted the data: Nagelkerke $R^{2}=0.338$ and Hosmer \& Lemeshow test $P$-value $=0.131 ; 71.9 \%$ of individuals were adequately classified by the model. There was a positive relationship between waterpipe smoking and chronic bronchitis $(\mathrm{ORa}=2.56$, 95\% CI: $1.29-5.08, P=0.007)$. In addition, older age, number of smokers in the family, lower education, ever living close to a busy road, ever living close to a local power plant, and heating home 


\begin{tabular}{|c|c|c|c|c|}
\hline \multirow[t]{2}{*}{ Dose } & Controls $(n=559)$ & Cases $(n=274)$ & $P$-value & OR $(95 \% \mathrm{Cl})$ \\
\hline & No. (\%) & No. (\%) & & \\
\hline Previous cigarette smoking (pack-years) ${ }^{a}$ & $(n=342)$ & $(n=131)$ & $<0.001$ & \\
\hline$<1$ & $256(74.9)$ & $16(12.2)$ & & 1.00 \\
\hline $1-18$ & $41(12.0)$ & $17(13.0)$ & & $6.63(3.11-14.16)$ \\
\hline $18.1-56$ & $32(9.4)$ & $47(35.9)$ & & $23.50(11.95-46.20)$ \\
\hline$>56$ & $13(3.8)$ & $51(38.9)$ & & $62.77(28.46-138.46)$ \\
\hline Previous waterpipesmoking (waterpipe-years) ${ }^{b}$ & $(n=283)$ & $(n=52)$ & $<0.001$ & \\
\hline$<0.1$ & $255(90.1)$ & $17(32.7)$ & & 1.00 \\
\hline $0.1-29.9$ & $16(5.7)$ & $10(19.2)$ & & $9.38(3.70-23.77)$ \\
\hline$\geq 30$ & $12(4.2)$ & $25(48.1)$ & & $31.25(13.42-72.78)$ \\
\hline Current cigarette smoking (pack-years) ${ }^{a}$ & $(n=396)$ & $(n=151)$ & $<0.001$ & \\
\hline$<1$ & $270(68.2)$ & $25(16.6)$ & & 1.00 \\
\hline $1-18$ & $57(14.4)$ & $13(8.6)$ & & $2.46(1.19-5.10)$ \\
\hline $18.1-45$ & $49(12.4)$ & $39(25.8)$ & & $8.60(4.78-15.46)$ \\
\hline$>45$ & $20(5.1)$ & $74(49.0)$ & & $39.96(21.03-75.92)$ \\
\hline Current waterpipe smoking (waterpipe-years) ${ }^{b}$ & $(n=341)$ & $(n=42)$ & $<0.001$ & \\
\hline$<0.1$ & $261(76.5)$ & $18(42.9)$ & & 1.00 \\
\hline $0.1-19.9$ & $50(14.7)$ & $4(9.5)$ & & $1.16(0.377-3.57)$ \\
\hline$\geq 20$ & $30(8.8)$ & $20(47.6)$ & & $9.67(4.61-20.27)$ \\
\hline Previous waterpipe frequency (waterpipe/week) & $(n=286)$ & $(n=54)$ & $<0.001$ & \\
\hline$<0.1$ & $256(89.6)$ & $17(31.5)$ & & 1.00 \\
\hline $0.1-3$ & $15(5.2)$ & $12(22.2)$ & & $12.05(4.88-29.75)$ \\
\hline$>3$ & $15(5.2)$ & $25(46.3)$ & & $25.10(11.20-56.23)$ \\
\hline Previous waterpipe duration (years) & $(n=286)$ & $(n=54)$ & $<0.001$ & \\
\hline$<0.1$ & $258(90.2)$ & $19(35.2)$ & & 1.00 \\
\hline $0.1-9.9$ & $16(5.6)$ & $10(18.5)$ & & $8.49(3.39-21.24)$ \\
\hline$\geq 10$ & $12(4.2)$ & $25(46.3)$ & & $28.29(12.32-64.95)$ \\
\hline Current waterpipe frequency (waterpipe/week) & $(n=345)$ & $(n=42)$ & 0.001 & \\
\hline$<0.1$ & $256(74.2)$ & $17(40.5)$ & & 1.00 \\
\hline $0.1-2$ & $35(10.1)$ & $4(9.5)$ & & $1.72(0.55-5.41)$ \\
\hline $2.1-7$ & $52(15.1)$ & $19(45.2)$ & & $5.50(2.68-11.29)$ \\
\hline$>7$ & $2(0.6)$ & $2(4.8)$ & & $15.06(2.00-113.58)$ \\
\hline Current waterpipe duration (years) & $(n=345)$ & $(n=42)$ & $<0.001$ & \\
\hline$<0.1$ & $265(76.8)$ & $18(42.9)$ & & 1.00 \\
\hline $0.1-5$ & $39(11.3)$ & $2(4.8)$ & & $0.76(0.17-3.38)$ \\
\hline 5.1-10 & $34(9.9)$ & $15(35.7)$ & & $6.50(3.00-1.63)$ \\
\hline$>10$ & $7(2.0)$ & $7(16.7)$ & & $14.72(14.72-46.56)$ \\
\hline
\end{tabular}

${ }^{a}$ Cumulative/day; Cumulative/week.

$O R=$ odds ratio; $C I=$ confidence interval.

by hot air were associated with chronic bronchitis. No logistic regression could be run on never cigarette smokers alone because the model inadequately fit the data.

In the current waterpipe smokers subgroup when taking waterpipe dependence as a major independent variable $(n=110 ; 23$ chronic bronchitis cases and 87 controls), the final model adequately fitted the data: Nagelkerke $R^{2}=0.722$ and Hosmer \& Lemeshow test $P$-value $=0.269$; $93.6 \%$ of individuals were adequately classified by the model. Waterpipe dependence was associated with an increase in the odds of chronic bronchitis but this was not statistically significant $(\mathrm{ORa}=5.14,95 \%$ CI: $0.81-32.62, P=0.083)$. Only older age $(\mathrm{ORa}=2.74,95 \% \mathrm{CI}: 1.50-5.02, \mathrm{P}$ $=0.001)$ and heating home by hot air 


\begin{tabular}{|c|c|c|c|}
\hline Population/subgroup & Major independent variables \& covariates & ORa $(95 \% \mathrm{Cl})$ & $P$-value \\
\hline \multirow[t]{9}{*}{ All individuals } & Ever smoking (> 20 WP-years) & $2.75(1.48-5.09)$ & 0.001 \\
\hline & Older age & $1.57(1.39-1.77)$ & $<0.001$ \\
\hline & Ever cigarette smoking & $14.05(8.07-24.46)$ & $<0.001$ \\
\hline & Lower education & $1.45(1.21-1.75)$ & $<0.001$ \\
\hline & Ever living close to a busy road & $2.07(1.36-3.16)$ & 0.001 \\
\hline & Ever living close to a power plant & $1.50(0.96-2.33)$ & 0.075 \\
\hline & Air conditioning on heating mode & $2.25(1.14-4.42)$ & 0.019 \\
\hline & Heating home other than electrically & $1.54(1.03-2.32)$ & 0.036 \\
\hline & Passive smoking inside the home & $1.88(1.23-2.88)$ & 0.004 \\
\hline \multirow[t]{7}{*}{ All WP smokers } & Smoking (> 20 WP-years) & $5.65(1.58-20.23)$ & 0.008 \\
\hline & Older age & $2.00(1.36-2.95)$ & $<0.001$ \\
\hline & Ever cigarette smoking & $412.01(25.85-6565.31)$ & $<0.001$ \\
\hline & Female gender & $5.02(1.32-19.08)$ & 0.018 \\
\hline & Lower education & $4.03(1.70-9.52)$ & 0.002 \\
\hline & Ever living close to a local power plant & $15.01(2.64-85.44)$ & 0.002 \\
\hline & Air conditioning on heating mode & $9.48(1.24-72.52)$ & 0.030 \\
\hline \multirow[t]{7}{*}{ Cigarette smokers } & Ever smoking (> 20 WP-years) & $2.56(1.29-5.08)$ & 0.007 \\
\hline & Number of smokers in the family & $1.34(1.10-1.63)$ & 0.004 \\
\hline & Older age & $1.56(1.37-1.78)$ & $<0.001$ \\
\hline & Lower education & $1.29(1.05-1.58)$ & 0.015 \\
\hline & Ever living close to a busy road & $1.66(1.06-2.60)$ & 0.026 \\
\hline & Ever living close to a local power plant & $1.92(1.18-3.12)$ & 0.009 \\
\hline & Air conditioning on heating mode & $2.22(1.06-4.66)$ & 0.034 \\
\hline \multirow[t]{5}{*}{ Current WP smokers } & Waterpipe dependence ( $\geq 10$ on LWDS-11) & $5.14(0.81-32.62)$ & 0.083 \\
\hline & Older age & $2.74(1.50-5.02)$ & 0.001 \\
\hline & Female gender & $4.45(0.72-27.73)$ & 0.110 \\
\hline & Air conditioning on heating mode & $12.96(1.06-158.27)$ & 0.045 \\
\hline & Central heating & $4.12(0.73-23.41)$ & 0.110 \\
\hline
\end{tabular}

OR $a=$ adjusted odds ratio; $C l=$ confidence interval. LWDS-11 = Lebanon Waterpipe Dependence Scale - 11.

$(\mathrm{ORa}=12.96,95 \% \mathrm{CI}: 1.06-158.27$, $P=0.045)$ were significantly associated with chronic bronchitis in this subgroup. The interaction term between cigarette and waterpipe dependence gave no significant result and it was removed from the model.

\section{Discussion}

This is, to our knowledge, the first case-control study that thoroughly looked at the relationship between waterpipe smoking, dependence and chronic bronchitis. At first sight, waterpipe smoking seems less harmful than cigarette, particularly in current waterpipe smokers. The reverse causality concept could explain this whereby current waterpipe smokers continue to smoke as long as they are healthy. However, the risk of chronic bronchitis was high in current waterpipe-dependent smokers versus non-smokers and non-waterpipe-dependent individuals. Although comparable results have not been reported in the literature, these results are analogous to those found by other researchers for cigarette smoking, where tobacco dependence increases the risk of COPD; this finding is explained by genetic links between tobacco dependence and respiratory disease propensity
$[28,29]$. Similar explanations may be applied to our findings.

We found a strong association between the risk of chronic bronchitis and being an ex-waterpipe smoker, although still less than that of ex-cigarette smokers. A cumulative dose of 20 waterpipeyears was also particularly implicated in increasing the risk of chronic bronchitis. Mixed smoking seemed to pose a particular risk: waterpipe smoking increased the risk of chronic bronchitis in cigarette smokers, which suggests a synergistic interaction between cigarette and waterpipe smoking is probable. The reason why this interaction gave no significant results in stratified analyses and was not 
retained in the final statistical models may be because of the small number of individuals after stratification. To our knowledge, no studies have ever examined the interaction between cigarette and waterpipe smoking and respiratory diseases; specific studies will be required to clearly show this interaction on lung diseases, including chronic bronchitis.

Other findings of our study also deserve attention: we found that older age, female gender, lower education, home heating by solid or liquid fossil fuels (not electrically), exposure to passive smoking at home in particular and ever living close to busy roads and a local power plant all increased the risk of chronic bronchitis. These characteristics and exposures have already been shown to increase the risk of chronic bronchitis and COPD and have been identified as risk factors in the GOLD recommendations [30].

Thus, we were able to show that waterpipe smoking increases the risk of chronic bronchitis. Although causality relationship cannot be demonstrated, there are internal causality factors that increase its likelihood, such as the dose-effect relationship and multivariate analyses in different subgroups. Moreover, some external causality criteria also exist, such as the biological plausibility [5] and the consistency of results with other researchers: our results are in line with associations found between waterpipe smoking and chronic bronchitis (compared to cigarette smoking) in Syrian women [12] and a systematic review that showed that waterpipe smoking was significantly associated with "respiratory illness", without further specifications
[13]. Another study reported higher pulmonary permeability $[8]$ and lower mucociliary clearance in Turkey waterpipe smokers (versus cigarette smokers and passive smokers) [31].

There are some limitations to our study that should be noted. First the overall waterpipe smoking in this relatively older population (age $>40$ years) was low, which decreased the power of the study in several of the analyses, particularly the multivariate ones, leading to wide confidence intervals. Second, there is a possibility of selection bias since the controls were chosen within the hospitals where cases were recruited. Differences in hospitals and physicians' reputation may affect this selection and therefore cases may differ geographically from controls (because of the reputation of a physician, cases may come from all over the country, while a less well known physician may only have local clients). Moreover, controls had mixed non-respiratory diagnoses and are not comparable to the general population, while cases and controls had geographical comparability or belonged sometimes to the same family: all this could lead to underestimation of the expected associations.

Individuals with lower educational levels generally have a lower probability of responding, and they also have a higher likelihood of waterpipe and cigarette smoking. This may introduce a selection bias of more educated persons, but we would not expect this bias to be differential. The pulmonologists recruiting the participants were unaware of their exposure status, especially the different types of exposure. This may decrease selection bias, although it cannot be totally excluded. A classification bias is also possible since exposure was only measured by the questionnaire, without further evaluation; as in all case-control studies, this may be subject to recall and subjectivity bias which may decrease the observed associations.

To minimize confounding, many other exposures that would be suspected of being associated with chronic bronchitis were taken into account in the logistic regression; however, residual confounding is still possible due to unmeasured variables.

Thus, further studies are necessary to overcome these weak points and confirm our findings. Prospective cohort studies in closed populations to study the pathophysiological changes and disease development that could occur in waterpipe smokers compared to non-smokers, cigarette smokers and passive smokers would provide robust data but they are more costly. Moreover, although we think our findings could be extrapolated to other populations in the region, we suggest comparative studies to rule out the effect genetic and social environment interactions on the association between waterpipe smoking and chronic bronchitis.

\section{Conclusion}

In conclusion, besides cigarette smoking, waterpipe dependence, measured by the validated by LWDS-11 score, is a dangerous behaviour, and exposed individuals have an increased risk of chronic bronchitis. Further studies are necessary to confirm our findings.

\section{References}

1. Martinasek MP, McDermott RJ, Martini L. Waterpipe (hookah) tobacco smoking among youth. Current Problems in Pediatric and Adolescent Health Care, 2011, 41:34-57.

2. Maziak W. The global epidemic of waterpipe smoking. Addictive Behaviors, 2011, 36:1-5.
3. Serota, J. A pack in 30 minutes. Journal of Pediatric Health Care, 2007, 21(3):180-181 \& 209-210.

4. Chouachi K. The medical consequences of narguile (hookah, shisha) use in the world. Revue d'Épidémiologie et de Sante Publique, 2007, 55:165-170. 
5. Advisory note. Waterpipe tobacco smoking: health effects, research needs and recommended actions by regulators. WHO Study Group on Tobacco Product Regulation (TobReg). Geneva, World Health Organization, 2005 (http://www.who.int/ tobacco/global_interaction/tobreg/Waterpipe\%20recommendation_Final.pdf, accessed 3 September 2012).

6. Knishkowy B, Amitai Y. Water-pipe (narghile) smoking: an emerging health risk behavior. Pediatrics, 2005, 116:e113-e119.

7. Tamim $\mathrm{H}$ et al. Tobacco use by university students, Lebanon 2001. Addiction (Abingdon, England), 2003, 98:933-939.

8. Aydin A et al. Water-pipe smoking effects on pulmonary permeability using technetium-99m DTPA inhalation scintigraphy. Annals of Nuclear Medicine, 2004, 18(40):285-289.

9. El Hakim IE, Uthman MA. Squamous cell carcinoma and keratoacanthoma of the lower lip associated with "Goza" and "Shisha" smoking. International Journal of Dermatology, 1999, 38:108-110.

10. Al Fayez SF et al. Effects of sheesha and cigarette smoking on pulmonary function of Saudi males and females. Tropical and Geographical Medicine, 1988, 40:115-123.

11. Nuwayhid IA et al. Waterpipe (hubble-bubble) smoking, low birth weight, and other pregnancy outcomes. American Journal of Epidemiology, 1998, 148:375-383.

12. Mohammad Y, Kakah M, Mohammad Y. Chronic respiratory effect of narguileh smoking compared with cigarette smoking in women from the East Mediterranean region. International Journal of Chronic Obstructive Pulmonary Disease, 2008, 3:405-414.

13. Akl EA et al. The effects of waterpipe tobacco smoking on health outcomes: a systematic review. International Journal of Epidemiology, 2010, 39:857-859.

14. Radwan GN et al. Review on water-pipe smoking. Journal of the Egyptian Society of Parasitology, 2003, 33(Suppl.):1051-1071.

15. Akl EA et al. The prevalence of waterpipe tobacco smoking among the general and specific populations: a systematic review. BMC Public Health, 2011, 11:244.

16. Nakkash RT, Khalil J, Afifi RA. The rise in narghile (shisha, hookah) waterpipe tobacco smoking: a qualitative study of perceptions of smokers and non smokers. BMC Public Health, 2011, 11:315.

17. Salameh P, Waked M, Aoun Z. Narguileh smoking: Construction and validation of the LWDS-11 dependence scale. Nicotine \& Tobacco Research, 2008, 10:148-159.

18. Salameh P, Aoun Z, Waked M. Saliva cotinine and exhaled carbon monoxide in real life narghile (waterpipe) smokers: a post hoc analysis. Tobacco Use Insights, 2009, 2:1-10.
19. Waked M, Khayat G, Salameh P. Chronic obstructive pulmonary disease prevalence in Lebanon: a cross-sectional descriptive study. Clinical Epidemiology, 2011, 3:1-9.

20. Vestbo J. Chronic bronchitis: should it worry us? Chronic Respiratory Disease, 2004, 1:173-176.

21. Waked M, Salameh P, Aoun Z. Water-pipe (narguile) smokers in Lebanon: a pilot study. Eastern Mediterranean Health Journal, 2009, 15:432-442.

22. Brunton $\mathrm{S}$ et al. Acute exacerbation of chronic bronchitis: a primary care consensus guideline. American Journal of Managed Care, 2004, 10:689-696.

23. Buist $\mathrm{S}$ et al. Global strategy for the diagnosis, management and prevention of chronic obstructive pulmonary disease. Global Initiative for Chronic Obstructive Lung Disease Inc., 2006.

24. Moolchan ET et al. The Fagerström test for nicotine dependence and the diagnostic interview schedule: do they diagnose the same smokers? Addictive Behaviors, 2002, 27:101-113.

25. Ferris BG. Epidemiology standardization project. American Review of Respiratory Disease, 1978, 118:1-88.

26. De Meneses-Gaya IC et al. Psychometric properties of the Fagerström test for nicotine dependence. Jornal Brasileiro de Pneumologia, 2009, 35:73-82.

27. Maziak W et al. Tobacco smoking using a waterpipe: a reemerging strain in a global epidemic. Tobacco Control, 2004, 13:327-333.

28. Jiménez-Ruiz CA et al. and the IBERPOC study investigators. Smoking characteristics: differences in attitudes and dependence between healthy smokers and smokers with COPD. Chest, 2001, 119:1365-1370.

29. Jiménez-Ruiz $\mathrm{C}$ et al. Can cumulative tobacco consumption, FTND score, and carbon monoxide concentration in expired air be predictors of chronic obstructive pulmonary disease? Nicotine \& Tobacco Research, 2004, 6:649-653.

30. Global Strategy for the Diagnosis, Management, and Prevention of Chronic Obstructive Pulmonary Disease (updated 2009).Global initiative for chronic Obstructive Lung Disease (GOLD) (http://www.goldcopd.org/uploads/ users/files/GOLDReport_April112011.pdf, accessed 9 September 2012).

31. Köseoğlu $\mathrm{N}$ et al. Nargile, sigara ve pasif içiciliğin mukosiliyer klerens uzerindeki etkileri [The effects of water-pipe, cigarette and passive smoking on mucociliary clearance]. Tüberküloz ve Toraks Dergisi, 2006, 54:222-228. 